\title{
Mechanical Properties of Epoxy Resin - Fly Ash Composite
}

\section{Manoj Singla ${ }^{1}$ and Vikas Chawla ${ }^{2}$}

\author{
${ }^{1}$ Department of Mechanical Engineering, R.I.E.I.T., Railmajra, Distt. Nawanshahr (Pb.)-144533, \\ INDIA \\ ${ }^{2}$ Department of Materials \& Metallurgical Engineering, I.I.T. Roorkee (Uttaranchal), INDIA
}

\section{Contact: ${ }^{1}$ manojsingla77@gmail.com, ${ }^{2}$ vikkydmt@iitr.ernet.in}

\begin{abstract}
There has been significant increase in use of glass fibre reinforced composites as structural materials in naval mine countermeasure surface ships. Sea mines when detonated emit underwater shock waves, which could impart severe loading to naval ship structure; there are attempts to model the response of a ship structure to this loading. For the model to be accurate \& useful material property data determined experimentally by taking different weight percentage of glass fibers (E-300, mat form) with epoxy resin \& comparison with fly ash reinforced composite. Specimens in the form of cube of size 10X10X10 (mm's) are used \& results are presented. Fracture behaviour of composite can also be studied using SEM. SEM analysis is done to observe distribution of fly ash particles in matrix, resin fly ash interface, glass fibre matrix interface, glass fibre distribution etc,.
\end{abstract}

Key Words: PMC'S, GFR

\section{INTRODUCTION}

Ash residues are wastes of coal fired plants and they are produced at the boiler outlets of plants, these including fly ashes and bottom ashes [1]. The demand for the light weight materials such as for surfaces of ships had led to the development of fly -ash based thermosetting resins [2-6]. In fibre epoxy composites the addition of fly ash led to a reduction of the density and increase in modulus of composites [4]. At present, epoxy resins are widely used in various engineering and structural applications such as electrical industries, and commercial and military aircrafts 
industries. In order to improve their processing and product performances, and to reduce cost, various fillers are introduced into the resins during processing [7].

\subsection{Matrix material for PMCs}

Matrix materials or resins in case of polymer matrix composites can be classified according to their chemical base i.e. thermoplastic or thermosets. Thermoplastics have excellent toughness, resilience and corrosion resistance but have fundamental disadvantage compared to thermosetting resins, in that they have to be molded at elevated temperature. The main thermoplastic used in fiber reinforced plastics are unsaturated polyesters which have lower cost but are usually not as strong as thermoset plastics like epoxy resins. Hence the main research effort is concentrated on thermosetting plastics.

Thermosetting plastics or thermosets are formed with a network molecular structure of primary covalent bonds. Some thermosets are cross-linked by heat or a combination of heat and pressure. Others may be cross-linked by chemical reaction, which occurs at room temperature.

\subsection{Epoxy Resins}

Epoxy resins are the most commonly used thermoset plastic in polymer matrix composites. Epoxy resins are a family of thermoset plastic materials which do not give off reaction products when they cure and so have low cure shrinkage. They also have good adhesion to other materials, good chemical and environmental resistance, good chemical properties and good insulating properties. The epoxy resins are generally manufactured by reacting epichlorohydrin with bisphenol. Different resins are formed by varying proportions of the two: as the proportion of epichlorohydrin is reduced the molecular weight of the resin is increased.
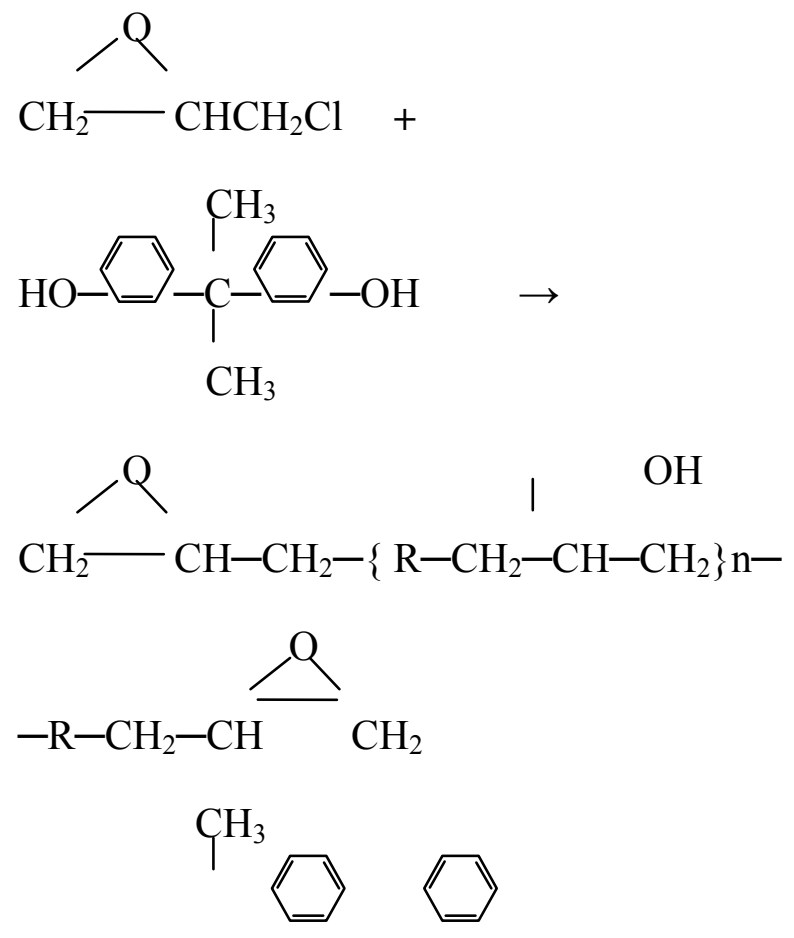


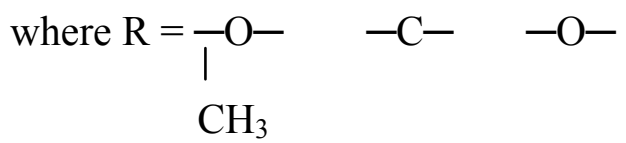

The general reactive group in epoxies is $\mathrm{ECHOCH}_{2}$.

\subsection{Curing of Epoxy Resins}

Epoxy resins are cured by means of a curing agent, often referred as catalysts, hardeners or activators. Often amines are used as curing agents. In amine curing agents, each hydrogen on an amine nitrogen is reactive and can open one epoxide ring to form a covalent bond.

\subsection{Fiber Matrix Interface}

The structure and properties of reinforcement matrix interface plays a major role in mechanical and physical properties of the composite materials. In particular large difference between the elastic properties of the matrix and fiber has to be communicated through interface. Many theories have been proposed for these interface characters and coupling agents.

\subsection{Fly Ash as a Filler Material}

Flyash is a coal combustion byproduct, which accumulates due to electrostatic precipitation of the flue gases in thermal power plant. When coal is burnt in thermal power plant the ash is carried forward in flue gases as fused particles, which solidifies as a spherical particle. Most of these spherical particles have a gas bubble at the centre. The constituents of flyash particles as obtained from coal in Britain are silica (59.5\%), Alumina (20.3\%), $\mathrm{FeO} / \mathrm{Fe}_{2} \mathrm{O}_{3}(6.5 \%)$, remaining being $\mathrm{FeO}, \mathrm{MgO}$ and unburnt coal etc.

Flyash depending upon the source of coal, contain different proportions of silica, alumina, oxides of iron, calcium, magnesium etc along with elements like carbon, $\mathrm{Ti}, \mathrm{Mg}$, etc. So the flyash has properties combined of spherical particles and that of metals and metal oxides.

Filler materials are generally the inert materials which are used in composite materials to reduce material costs, to improve mechanical properties to some extent and in some cases to improve processability.

Blending of polymeric materials (PVC \& PVB) leads to increased impact strength. Reinforcement of polymer matrix with glass fiber leads to general improvement of mechanical properties.

Polymer matrix composites are used in greatest diversity in light of their less cost, ease of fabricability, higher specific strength, design flexibility and lightweight. 


\section{EXPERIMENTATION}

Commercially available ARALDITE LY 554 along with hardner HY 951 was used as matrix material in fabrication of different slabs. For processing the mix ratio (by weight) of ARALDITE (100 parts) and hardner (10 parts) are used as specified.

\subsection{Raw Material Used}

Flyash:- Silica (59.5\%), Alumina (20.3\%), $\mathrm{FeO} / \mathrm{Fe}_{2} \mathrm{O}_{3}(6.5 \%)$, remaining being $\mathrm{FeO}, \mathrm{MgO}$ and unburnt coal etc.

Epoxy resin:- Araldite- LY- 554

$1.10-1.15 \mathrm{gm} / \mathrm{cc}$

Hardner :- HY-951

$0.97-0.99 \mathrm{gm} / \mathrm{cc}$

Glass fiber:- E-glass (E-300) Mat

$2.54 \mathrm{gm} / \mathrm{cc}$

\subsection{Fabrication of Material}

The fabrication of the polymer matrix composite was done at room temperature. The required ingredients of resin, hardner, fly ash and glass fibre were mixed thoroughly in beaker as shown and the mixture so made was transferred to mould cavity of the mould and the mould tightened with the help of nuts \& bolts.

\subsubsection{Mould preparation}

Two wooden moulds of size 154 X 78 X 12 (mms) were used for casting of polymer matrix composite slabs. The moulds made of pressed wood. The mould comprises of two plates one top \& other bottom \& third rectangular mould cavity inside. After that by placing the three pieces together drill the holes $\&$ then it has to be tightened by nuts $\&$ bolts.

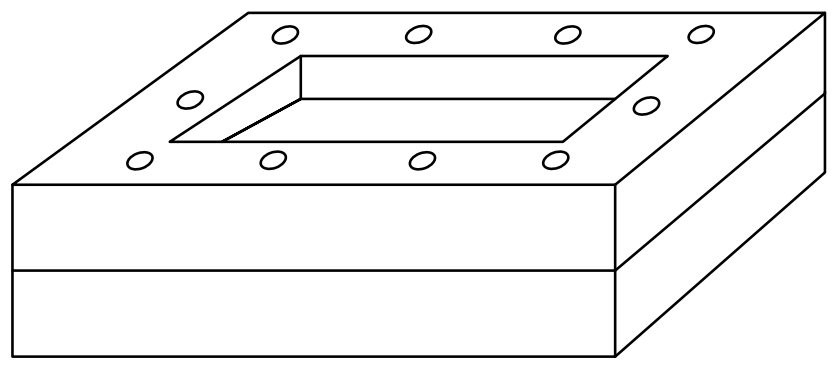

Fig. 1. Mould Assembly. 


\subsubsection{Dough preparation}

The required mixture of resin $\&$ hardner were made by mixing them in (10:1) parts in a beaker by stirring the mixture in a beaker by a rod taking into care that no air should be entrapped inside the solution.

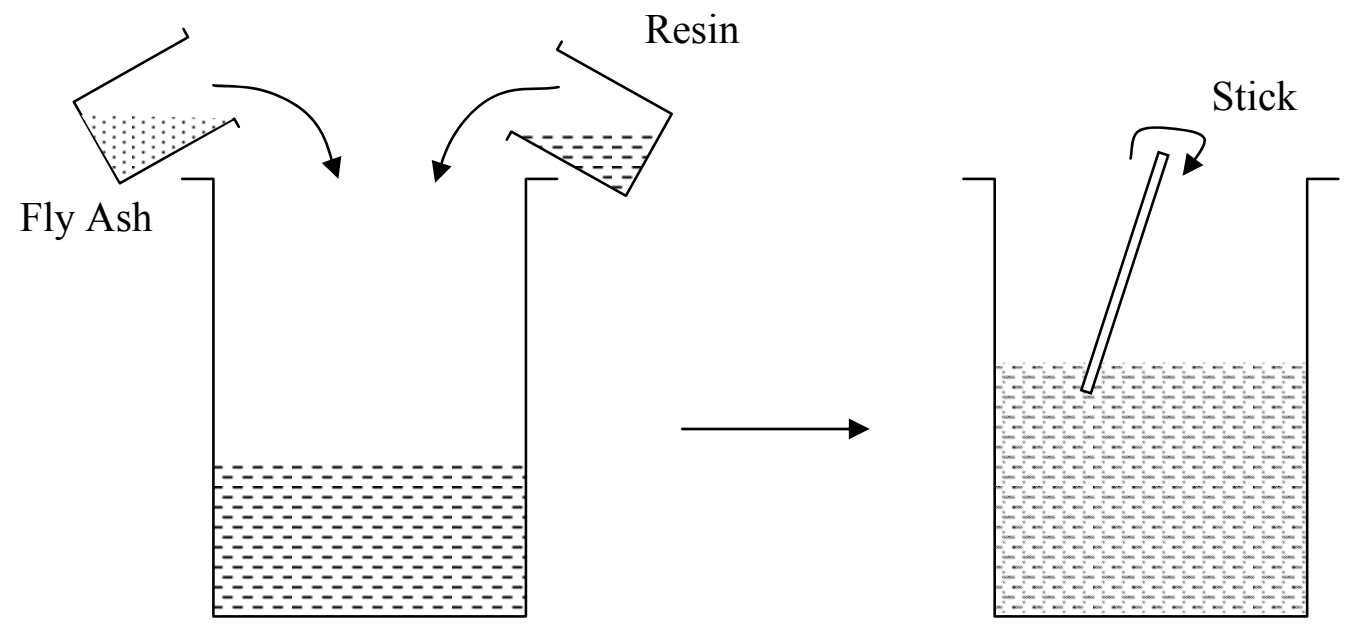

Fig. 2. Mixing of Fly Ash and Resin.

\subsubsection{Casting of slabs}

The dough prepared was transferred to mould cavity by care that the mould cavity should be thoroughly filled. Leveling was done to uniformly fill the cavity.

\subsubsection{Curing}

Curing was done at room temperature for approx. $24 \mathrm{hrs}$. After curing the mould was opened slab taken out of the mould and cleaned.

\subsubsection{Material composition}

Following nomenclature shown in Table 1 is used for identification of different compositions.

\subsubsection{Sample Preparation}

The cast slabs of the material were taken out of the mould \& then six samples were taken each for Compression \& Impact test of 10X10X10 (mms) \& 10X10X55 (mms) dimensions. 
Table 1. Nomenclature of material fabricated.

\begin{tabular}{|l|l|l|l|}
\hline $\begin{array}{l}\text { Material } \\
\text { Designation }\end{array}$ & $\begin{array}{l}\text { \% fly ash (by } \\
\text { weight) }\end{array}$ & $\begin{array}{l}\text { \% resin } \\
\text { weight) }\end{array}$ & (by glass fibre (by wt.) \\
\hline C1 & 30 & 70 & Nil \\
\hline C2 & 38 & 62 & Nil \\
\hline C3 & 46 & 54 & Nil \\
\hline C4 & 54 & 46 & Nil \\
\hline C5 & 38 & 60 & 2 \\
\hline
\end{tabular}

\subsection{Mechanical Properties}

Compression \& Impact tests were carried out using Universal Tensile testing machine \& Impact testing machine respectively.

\subsubsection{SEM Study of fractured surfaces}

SEM analysis of the post mechanical tests was carried out to observe distribution of fly ash particles in the matrix, resin fly ash interface, glass fibre distribution in the matrix, glass fibre matrix interface, deformation behaviour etc.

SEM analysis was done on JEOL, JSM 6100 at Sophisticated Analytical Instrumentation Facility, Central Instrumentation Laboratory, Panjab University, Chandigarh.

\section{RESULTS \& DISCUSSION}

Fabricated materials of different compositions of epoxy resin system have been tested under static \& dynamic loading conditions.

\subsection{Compression Test}

The values of compression strength of epoxy resin fly ash composite material with different $\%$ of fly ash is given in Table 2 .

The increase in compressive strength of epoxy resin fly ash composite with increase of fly ash may be attributed to hollowness of fly ash. The hollowness of fly ash particles increases the material capacity to increase the material capacity to increase energy [8]. 
Table 2. Comparison of compressive strength using different wt. \% of fly ash.

\begin{tabular}{|l|l|l|}
\hline Material Designation & \% fly ash (by weight) & Compressive strength (N/mm ${ }^{2}$ ) \\
\hline C1 & 30 & 84.3 \\
\hline C2 & 38 & 88.2 \\
\hline C3 & 46 & 96.2 \\
\hline C4 & 54 & 102.3 \\
\hline
\end{tabular}

\subsection{Impact Test}

The values of impact strength of epoxy resin fly ash composite material with different \% of fly ash is given in Table 3.

Table 3. Comparison of impact strength using different wt. \% of fly ash

\begin{tabular}{|l|l|l|}
\hline Material Designation & \% fly ash (by weight) & Impact strength (Joules) \\
\hline C1 & 30 & 0.92 \\
\hline C2 & 38 & 0.72 \\
\hline C3 & 46 & 0.52 \\
\hline C4 & 54 & 0.52 \\
\hline
\end{tabular}

Slight decrease in energy has been observed due to decreased availability of epoxy material to bond all the fly ash particles in the matrix. 


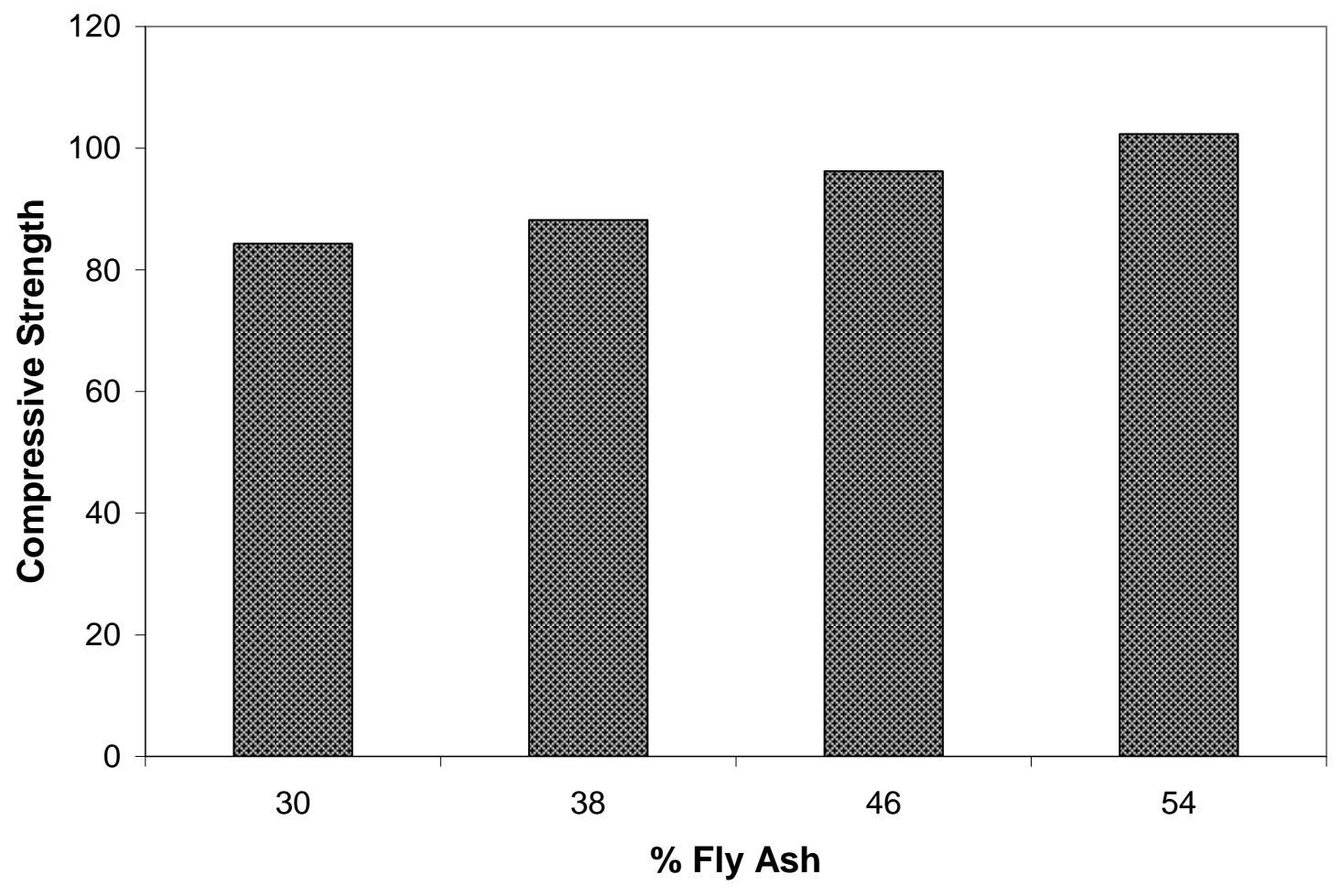

Fig. 3. Comparison of Compressive Strength.

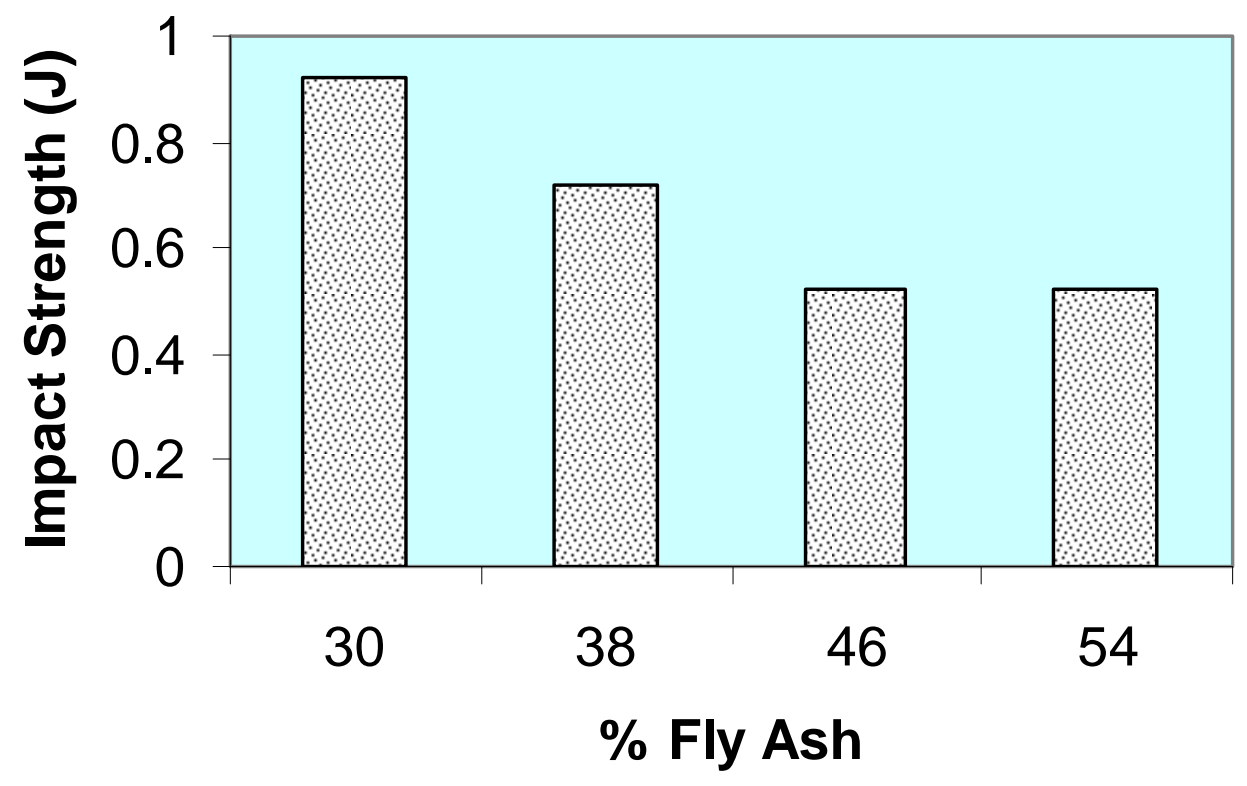

Fig. 4. Comparison of Impact Strength. 
Table 4. Compressive strength \& impact energy absorbed in impact test of glass reinforced resin fly ash material.

\begin{tabular}{|l|l|l|l|l|}
\hline $\begin{array}{l}\text { Material } \\
\text { Designation }\end{array}$ & Fly ash (wt. \%) & $\begin{array}{l}\text { Glass fibre (wt. } \\
\text { \%) }\end{array}$ & $\begin{array}{l}\text { Compressive } \\
\text { strength } \\
\text { (N/mm } \mathbf{m}^{2}\end{array}$ & $\begin{array}{l}\text { Impact } \\
\text { strength } \\
\text { (Joules) }\end{array}$ \\
\hline C5 & .8 & 2 & 104.7 & 4.2 \\
\hline
\end{tabular}

Table 5. Comparative properties of resin fly ash system \& glass reinforced resin fly ash composites.

\begin{tabular}{|l|l|l|l|l|}
\hline $\begin{array}{l}\text { Material } \\
\text { Designation }\end{array}$ & Fly ash (wt. \%) & $\begin{array}{l}\text { Glass fibre (wt. } \\
\text { \%) }\end{array}$ & $\begin{array}{l}\text { Compressive } \\
\text { strength } \\
\left(\mathbf{N} / \mathbf{m m}^{2}\right)\end{array}$ & $\begin{array}{l}\text { Impact } \\
\text { strength } \\
\text { (Joules) }\end{array}$ \\
\hline C2 & 38 & 00 & 88.2 & 0.72 \\
\hline C5 & 38 & 2 & 104.7 & 4.2 \\
\hline
\end{tabular}

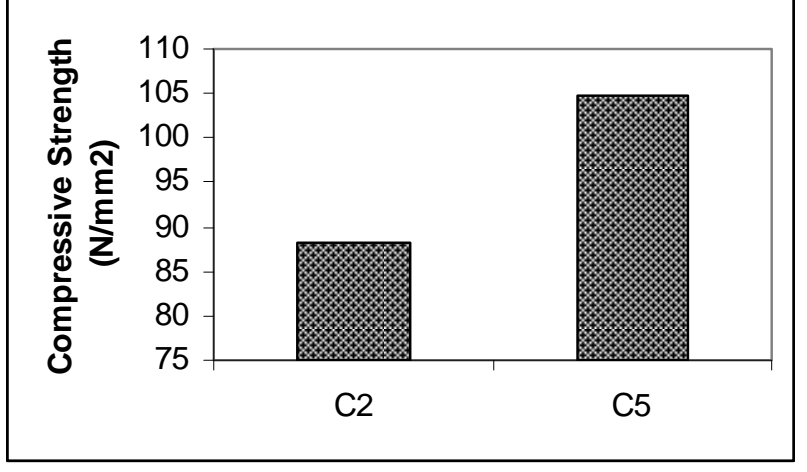

Fig. 5. Comparison of Compressive Strength

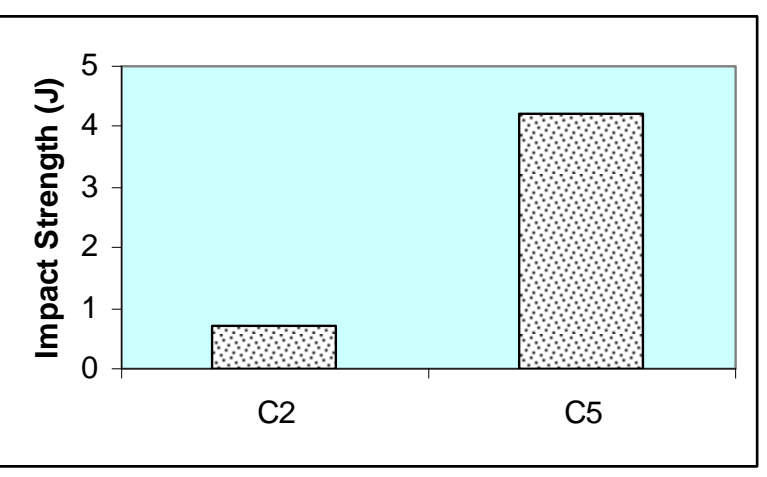

Fig. 6. Comparison of Impact Strength

There is increase in compressive strength \& energy absorbed during the impact test in glass reinforced resin fly ash composite. The increase in compressive strength is due to reinforcing action of the glass fibre. When load is applied the matrix material cannot flow due to presence of glass fibres. 


\subsection{SEM Study of Resin Fly Ash Composite}

In SEM analysis it has been found that flyash particles are uniformly distributed \& glass fibres are found to be randomly distributed. Fig. 7 shows some compatibility of glass fibres with the matrix material. SEM Photograph in Figure 8 shows the broken fractured surface of the glass fibre. SEM photograph in Fig. $9 \& 10$ shows uniform distribution of fly ash in the matrix.

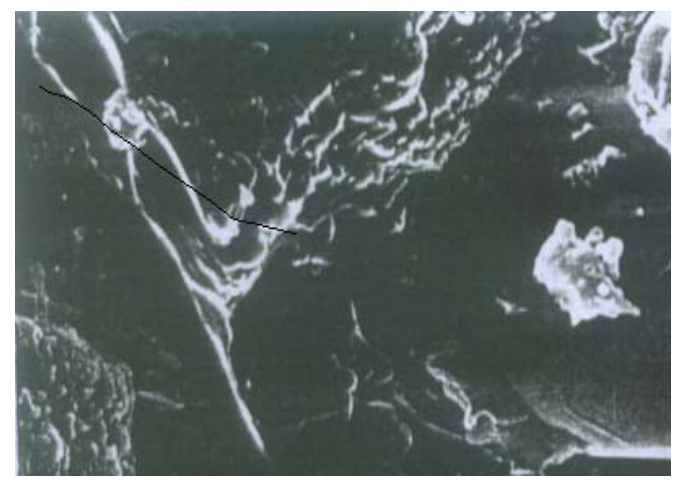

Fig. 7. SEM of glass fibres and matrix.

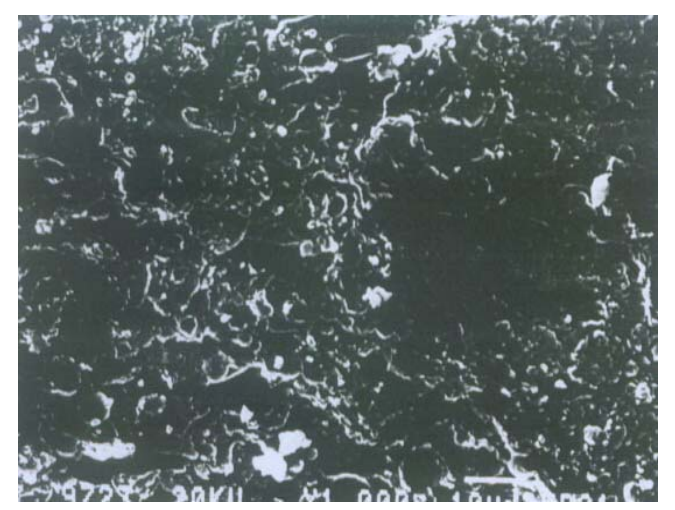

Fig. 9. Fly ash in matrix.

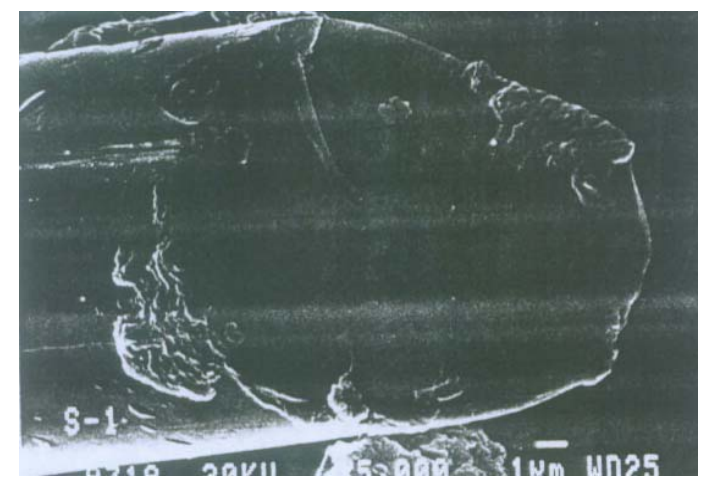

Fig. 8. Fractured surface of glass fibre.

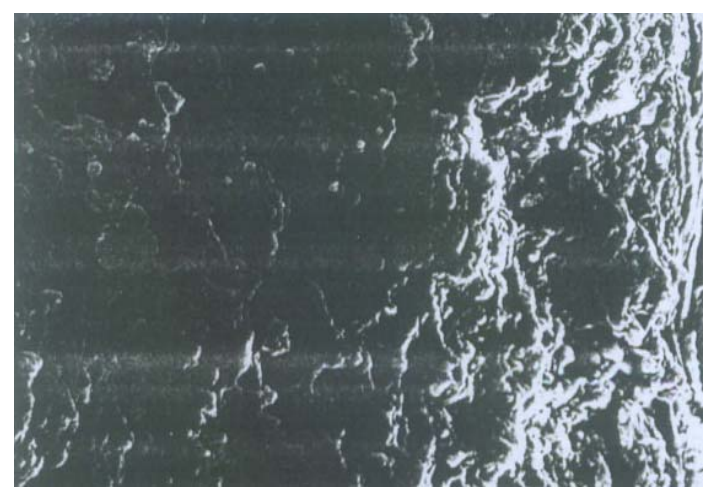

Fig. 10. Fly ash in matrix.

\section{CONCLUSION}

$>$ With the addition of fly-ash in epoxy resin -fly-ash composite the compressive strength has been found to increase with increase in fly ash particles. This increase is attributed to hollowness of fly-ash particles \& strong interfacial energy between resin \& fly-ash. 
After reinforcing glass fibre both compressive \& impact strength has been increased due to energy absorbed in fibre pull out.

In SEM analysis it has been found that fly-ash particles has been uniformly segregated.

\section{ACKNOWLEDGEMENT}

The author acknowledges with thanks the support provided by Department of Mechanical Engineering, RIEIT, Railmajra, Distt. Nawanshahr (PB) India.

\section{REFERENCES:}

1. National Report on Thailand Outstanding Technologist Award By Foundation of the Promotion of Science and Technology under the Patronage of H.M. the King, BKK, Thailand, October, 2002.

2. Chand N. SEM observations of fractured fly-polyester composites. J Mat Sci Lett 1988;7: $36-8$.

3. Kishore, Kulkarni SM, Sharathchandra S, Sunil D. On the use of an instrumented set-up to characterize the impact behavior of an epoxy system containing varying fly ash content. Polym Test 2002;21: 763-71.

4. Kulkarni SM, Kishore. Effect of filler-fiber interactions on compressive strength of fly ash and short-fiber epoxy composites. J Appl Polym Sci 2003;87:836-41.

5. Garde K, McGill WJ, Woolard CD. Surface modification of fly ash - characterization and evaluation as reinforcing filler in polyisoprene. Plast Rubb Compos 1999; 28:1-10.

6. Sombatsompop N, Thongsang S, Markpin T, Wimolmala E. Fly Ash Particles and Precipitated Silica as Fillers in Rubbers. I. Untreated Fillers in Natural Rubber and StyreneButadiene Rubber Compounds. J Appli Polym Sci 2004; 93:2119-30.

7. Huang Z.M. Tensile strength of fibrous composites at elevated temperature, Materials Science and technology, January 2000, vol 16. 81-93.

8. Gupta NB. Effect of filler addition on the compressive and impactproperties of glass fiber reinforced epoxy. Bull Mat Sci 2001;24: 219-23.

9. S T Peter,1998, Handbook of Composites, chapman \& hall publication.

10. PK Mallick,1997, composite materials engineering handbook, Maracel Dekker. 
11. Chamis, C C. Mechanics of load transfer at the interface (from matrix to fiber of composites) Interfaces in polymer matrix composites. (A75-24890 10-24) New York, Academic Press, Inc., 1974, p. 31-77.

12. Dash P K. Effect of Notch \& Environment on tensile strength of Bi-directional Carbon/Epoxy composite - An experimental study, Vol 82, May 2001

13. Ericsion P W \& Plueddeman E P. History background of interfaces-studies and theories \& composite materials Vol 6,1974 .

14. Lea and Desh, Chemistry of cements and concretes, Edward publication London.

15. Thomsons J L. The influence of Fibre properties of glass -fibre - reinforced polyamide6,6 Journal of composite materials, vol. 34 , no. 02/2000.

16. Shah Khan M.Z. Resistance of glass fibre reinforced polymer composites to increasing compressive strain rates and loading rates. Composites Part A: Applied Science and Manufacturing, Volume 31, Issue 1, January 2000, Pages 57-67.

17. Henry J. Jones. Glass fibre reinforced cement composites Part A 31 (2000) 391-403. 